residence time at lower substrate temperatures is probably partly responsible for the increased yields of hydrogen peroxide and oxygen evolved found under those conditions. Moreover, selectivity at this stage may be an influence underlying the ratio of peroxide to evolved oxygen.

R. L. Alluen

F. S. STONE

Department of Physical and Inorganic Chemistry, University of Bristol.

${ }^{1}$ Geib, K. H., and Harteck, P., Ber., 65, 1551 (1932).

2 Jones, R. A., and Winkler, C. A., Canad. J. Chem., 29, 1010 (1951).

${ }^{3}$ Batzold, J. S., Luner, C., and Winkler, C. A., Canad. J. Chem., 31, 262 (1953).

- Giguère, P. A., J. Chem. Phys., 22, 2085 (1954).

${ }^{5}$ McKinley, J. D., and Garvin, D., J. Amer. Chem. Soc., 77, 5802 (1055).

'Livingston, R., Ghormley, J., and Zeldes, H., J. Chem. Phys., 24, 483 (1956).

${ }^{7}$ Ghormley, J. A., J. Chem. Phys., 25, 599 (1956).

s Blackman, M., and Lisgarten, N. D., Proc. Roy. Soc., A, 239, 93 (1957).

- Frost, A. A., and Oldenberg, O., J. Chem. Phys., 4, 781 (1936).

${ }^{10}$ Foner, S. N., and Hudson, R. L., J. Chem. Phys., 23, 1364 (1955).

\section{Anion Exchange Behaviour of Yttrium}

IN a recent paper ${ }^{1}$, we have reported the uptake of thorium on a strong-base anion exchange resin from sulphate and carbonate solutions. It was also observed in this laboratory that a trace amount of yttrium-90 was adsorbed on such resin from ammonium sulphate, sulphuric acid and sodium carbonate solutions.

The resin employed was 'Dowex $1 \times-8$ ', consisting of 100-200 mesh beads. Before use, it was converted to the sulphate or carbonate form and then stored in a desiccator over a saturated solution of sodium bromide. Columns of $8-\mathrm{mm}$. diameter filled with $3 \mathrm{gm}$. of the resin were prepared. Yttrium-90 tracer, supplied as hydrochloric acid solution, was evaporated almost to dryness on a water-bath and dissolved in solutions of ammonium sulphate, sulphuric acid and sodium carbonate of various concentrations. For the measurements of radioactivities, the samples were prepared as follows: for column studies, one drop of the effluent was evaporated on a glass disk under an infra-red lamp, while, for equilibrium studies, yttrium-90 in the solution equilibrated with resin was coprecipitated with $5 \mathrm{mgm}$. of ferric iron and the radioactivity of the dried precipitate was noted.

Only column studies were carried out for ammonium sulphate and sulphuric acid solutions. The resin columns were first treated with simple ammonium sulphate or sulphuric acid solutions of certain concentrations. Then a 0.1 ml.-portion of yttrium-90 tracer solution was placed on the top of each column. The elution was carried out with ammonium sulphate or sulphuric acid solution at a rate of $0.3 \mathrm{ml}$. per minute.

From the elution curves obtained, the distribution coefficients were evaluated by the relationship,

$$
V=I+M \times K_{d}
$$

where $V$ is volume of effluent necessary to obtain the eluted yttrium in maximum concentration in the effluent, $I$ is the fractional interstitial space, $M$ is total amount of resin and $K_{d}$ is the distribution coefficient (radioactivity per gm. resin/radioactivity per ml. solution). The values of $K_{d}$ are shown in Table 1.
Table $1 . K_{d}$ VALUES FOR SULPHURIC
AOID AND AMMONIUM SULPHATE SOLUTIONS

Solution

$1 M$ Ammonium sulphate

$0 \cdot 1$ Ammonium sulphate

$0 \cdot 01 M$ Ammonium sulphate

$\begin{array}{ll}0.1 M \text { Sulphuric acid } & <1 \\ 0.01 M \text { Sulphuric acid } & \sim 1.5\end{array}$

Experiments were carried out at room temperature

Both column and equilibrium studies were carried out for carbonate solutions.

After the resin bed was treated with $0.1 M$ sodium carbonate solution, $10 \mathrm{ml}$. yttrium-90 solution was added to the top of the column. Then the column was washed with $20 \mathrm{ml}$. of $0.1 M$ sodium carbonate solution. No activity of yttrium-90 was detected in the effluent.

The adsorption of yttrium-90 from $1 M$ sodium carbonate solution was rather weak so that a $K_{d}$ of 6 was obtained by the column method as described above.

A weighed portion of the resin was allowed to stand overnight in a solution of sodium carbonate under consideration. Yttrium-90 tracer solution was added to the system. After the whole system was placed in glass-stoppered Erlenmeyer flasks, it was shaken on a mechanical shaker in a thermostat at $25^{\circ} \mathrm{C}$. until the exchange equilibrium was attained. The values of $K_{d}$ are given in Table 2 . It is remarkable that the adsorbability of yttrium-90 increases rapidly with decreasing carbonate concentration.

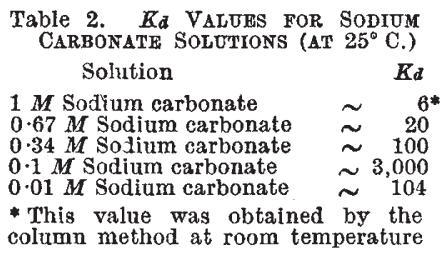

Details will be published elsewhere.

Nobufusa Sarto

TatsuYa Serine

Department of Chemistry,

Faculty of Science,

University of Tokyo. June 11 .

${ }^{1}$ Saito, N., and Sekine, T., Bull. Chem. Soc. Japan (in the press)

\section{A New Compound of Univalent Cobalt}

Polarographic behaviour of the ions $\mathrm{Co}$ (dipy) ${ }_{3}{ }^{3+}$ and $\mathrm{Co}$ (dipy) ${ }_{3}{ }^{2+}$ shows that they are reversibly reduced at the dropping mercury electrode to a compound of univalent cobalt which does not decompose in neutral aqueous or ethanolic solutions.

The redox potential, measured as half-wave potential, of the CoI.-CoII couple in the complex with dipyridyl was found to be $-0.91 \mathrm{~V}$. (vs. aqueous saturated calomel electrode) in a $1 M$ lithium chloride ethanolic solution and $-1.24 \mathrm{~V}$. (vs. saturated calomel electrode) in aqueous solution.

As the polarographic behaviour of the $\mathrm{Co}^{\mathrm{I}}$-_-CoII couple suggested that the complex of univalent cobalt with dipyridyl is stable in the solution, attempts were made to carry out the reduction in the solution and to isolate the complex.

As the starting compound, $\mathrm{Co}(\text { dipy })_{3}\left(\mathrm{ClO}_{4}\right)_{3} \cdot 3 \mathrm{H}_{2} \mathrm{O}$ (prepared according to Burstall and $\mathrm{Nyholm}^{ \pm}$) was 